\title{
Changes in Polyphenol Oxidase Activity During Rooting of Hardwood Cuttings in Three Grape Rootstocks Under Indian Conditions
}

\author{
J. Satisha*, P. Raveendran and N.D. Rokade \\ National Research Centre for Grapes, Pune, India - 412307 \\ Submitted for publication: July 2008 \\ Accepted for publication: September 2008 \\ Key words: Rootstocks; rooting; polyphenol oxidase; biochemical constituents
}

\begin{abstract}
Polyphenol oxidase (PPO) activity was investigated during rooting in cuttings from the rootstocks Dog ridge, $110 \mathrm{R}$ and St. George, belonging to different Vitis species. Enzyme activity and rooting ability were analysed. Significant differences were found in PPO activity among different rootstocks, with Dog ridge and $110 \mathrm{R}$ having the highest PPO activity during the initial period of planting, followed by a decrease in enzyme activity. In St. George, the enzyme activity was least during the initial periods, but it increased throughout the experiment. The initiation of rooting primordia was observed until 60 to 90 days after planting in Dog ridge and $110 \mathrm{R}$ rootstocks, while it was observed 120 days after planting in St. George, suggesting differences in the rooting behaviour of the rootstocks. The status of various biochemical components of the mother vines, such as total phenols, reducing sugars, carbohydrates, nitrogen, $\mathrm{C}: \mathrm{N}$ ratio, etc. were analysed to investigate the influence of these constituents on the rooting ability of the rootstocks apart from PPO activity.
\end{abstract}

Grapes are one of the commercially important fruit crops in India and are cultivated on approximately 60000 hectares, with an annual production of 1.2 to 1.4 metric tons (MT). Grapes are commercially propagated through hardwood cuttings. Cuttings are made from shoots that are one season old and have three to four nodes. They are planted in the media to induce rooting before being transplanted in the field. Dog ridge is one of the commercially important rootstock and is known for its drought tolerance. It is a more vigorous variety and Thompson Seedless grafted onto this rootstock is known to produce more vegetative growth at the cost of reproductive growth, thus reducing the yield per unit area. Another rootstock that is gaining popularity in India is $110 \mathrm{R}$, which is known for its drought and salt tolerance, apart from improving bud fruitfulness due to its moderate vigour. St. George is one of the important rootstocks for phylloxera resistance. It is moderately tolerant to drought on lightly textured soil and highly tolerant of moisture stress in deep soils. The rooting ability of rootstocks vary with the species, IBA concentration, and the biochemical composition of the mother vines (Satisha et al., 2007). Polyphenol oxidase is an enzyme present in all plant species that is involved in the rooting of cuttings. PPO is a nuclear-coded copper-containing enzyme, widely distributed in plant species, which catalyses the oxidation of phenols and quinones (Kim et al., 2001). Many workers have established the role of PPO during the rooting process. The activities of a number of enzymes change during the rooting process, and it has been suggested that some of these enzymes are involved in root initiation (Dalet \& Cornu, 1998; Gonazales et al., 1991). PPO can directly regulate the synthesis of phenolics and plays a role in the organisation and development of root primordia (Hahlbrock \& Grisebach, 1979). It has been reported that PPO plays an important role in cell division, differentiation and primordia development (Huystee \&
Cairns, 1982). In our earlier studies we could see the variation in rooting percentage and the number of days taken for sprouting in different grape rootstocks under conditions of similar propagation media and cultural practices. Hence, this investigation was taken up to study the PPO activity of three grape rootstocks belonging to different Vitis species.

\section{MATERIALS AND METHODS}

This experiment was conducted to study the rooting process of three different rootstocks belonging to different Vitis species. The rootstocks selected were Dog ridge (Vitis champinii), St. George (Vitis rupestris) and $110 \mathrm{R}$ (Vitis berlandierii $\times$ Vitis rupestris). Hardwood cuttings of 8 to $10 \mathrm{~mm}$ thick with four buds were prepared from shoots of the mother vines maintained at the rootstock block of the National Research Centre for Grapes, Pune. Pune is situated in the mid-west Maharashtra state, at an altitude of $559 \mathrm{~m}$, and lies on latitude $18.32^{\circ} \mathrm{N}$ and longitude $73.51^{\circ} \mathrm{E}$. From the mother plants identified for making cuttings, a few cuttings were used for the estimation of various biochemical parameters, such as total phenols, carbohydrates, nitrogen and $\mathrm{C} / \mathrm{N}$ ratio before planting in the rooting media.

\section{Preparation of cuttings and planting}

Cuttings were treated with cold water for 24 hours to leach out rooting inhibitors and were then dipped in $1000 \mathrm{ppm}$ indole butyric acid (IBA) for 30 to 60 seconds before planting in plastic trays filled with sand. The cuttings were kept in a dark room and periodically sprayed with water to encourage sprouting. Care was taken to insert at least one bud inside the sand media, leaving three buds above ground level. After 30 days, the cuttings were transplanted into polythene bags containing a potting mixture of soil, sand and farmyard manure (FYM) in the proportion of 2:1:1. Sprouting percentage was recorded 30 days after planting, while 


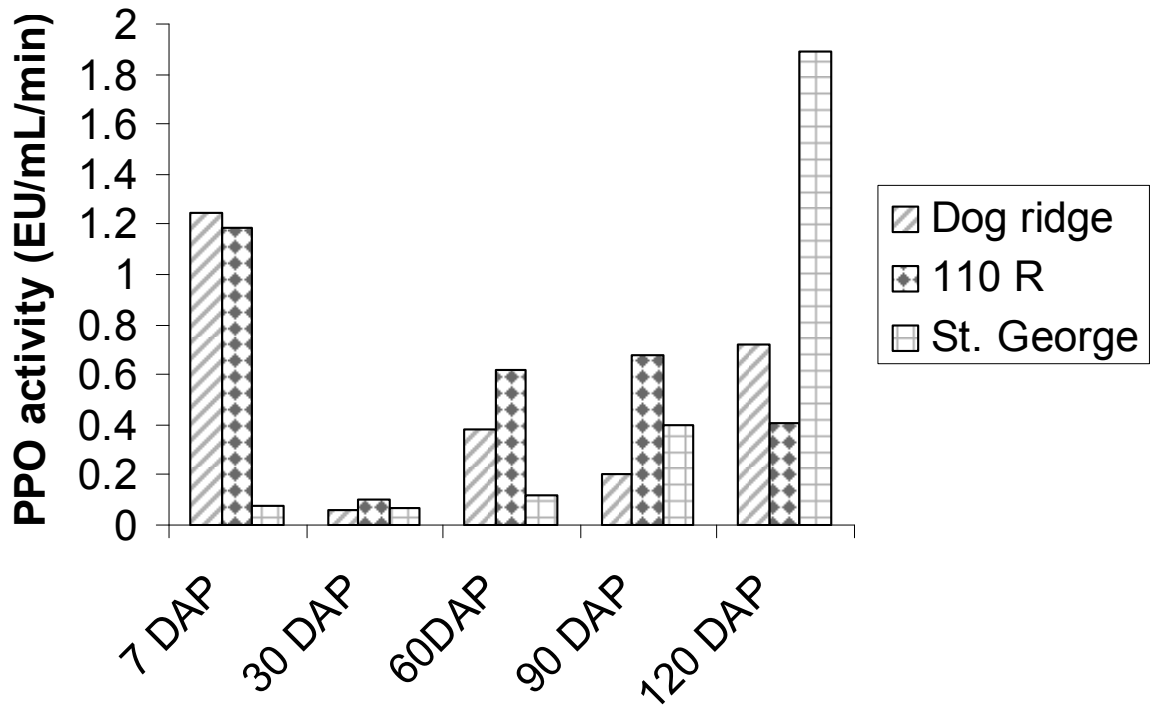

Days after palnting

\author{
FIGURE 1 \\ PPO activity $(\mathrm{EU} / \mathrm{mL} / \mathrm{min})$ in grape rootstocks during rooting.
}

TABLE 1

Biochemical constituents of rootstock cuttings at the time of planting.

\begin{tabular}{cccccc}
\hline Rootstocks & $\begin{array}{c}\text { Phenols } \\
(\mathbf{m g} / \mathbf{g})\end{array}$ & $\begin{array}{c}\text { Carbohydrates } \\
(\mathbf{m g} / \mathbf{g})\end{array}$ & $\begin{array}{c}\text { Nitrogen } \\
\mathbf{( \% )}\end{array}$ & C:N ratio & Reducing sugar $(\mathbf{m g} / \mathbf{g})$ \\
\hline Dog ridge & $34.91 \pm 2.78 \mathrm{a}$ & $57.16 \pm 2.76 \mathrm{~b}$ & $0.80 \pm 0.01 \mathrm{a}$ & $7.20 \pm 0.58 \mathrm{~b}$ & $33.30 \pm 4.24 \mathrm{a}$ \\
$\mathbf{1 1 0}$ R & $29.04 \pm 1.84 \mathrm{a}$ & $61.00 \pm 1.31 \mathrm{a}$ & $0.53 \pm 0.03 \mathrm{~b}$ & $11.50 \pm 1.10 \mathrm{a}$ & $31.29 \pm 1.98 \mathrm{~b}$ \\
St. George & $16.71 \pm 0.16 \mathrm{~b}$ & $53.00 \pm 5.58 \mathrm{c}$ & $0.69 \pm 0.02 \mathrm{a}$ & $7.68 \pm 0.16 \mathrm{~b}$ & $35.64 \pm 1.10 \mathrm{a}$ \\
\hline
\end{tabular}

$*$ The values are mean \pm SD of four replicates, and those marked with different alphabetic letters in the same column are significantly different at $\mathrm{p} \leq 0.05$.

observations of the number of root primordia were recorded at 30 -day intervals up to 120 days. Total root length was recorded at 120 days after planting in all three rootstocks.

\section{Estimation of biochemical composition}

The total phenolic content was determined using the FolinCiocalteu method (Singleton \& Rossi, 1965), using gallic acid as the standard. The concentration of the total phenolics was expressed as the gallic acid equivalent (GAE $\mathrm{mg} / \mathrm{g}$ ) of the lyophilised sample. Reducing sugar was estimated by the dinitro salicylic acid (DNSA) method, and carbohydrate and nitrogen were estimated by the anthrone and micro-kjeldhal methods respectively. The carbohydrate:nitrogen $(\mathrm{C}: \mathrm{N})$ ratio was derived using the respective values of carbohydrates and nitrogen.

\section{Determination of PPO activity}

The destruction method of sampling was followed wherein the basal portion of the shoot, along with the callus, was taken for the estimation of PPO activity. PPO activity was measured periodically at 30,60, 90 and 120 days after planting. Five grams of the root sample, along with the basal shoot portion, were homogenised by mixing the $10 \mathrm{~mL} 0.2 \mathrm{M}$ potassium phosphate buffer ( $\mathrm{pH} 7.0$ ) for PPO extraction. Homogenates were centrifuged for 10 minutes at $7244 \times \mathrm{g}$ under cold conditions. PPO activity was measured as per the methods of Haplin and Lee (1987). McIlvaine buffer $\left(0.2 \mathrm{M} \mathrm{Na}_{2} \mathrm{HPO}_{4} / 0.1 \mathrm{M}\right.$ citrate monohydrate in a proportion of 2.3:1) was adjusted to $\mathrm{pH} 6.5$ for the substrate preparation, and $1.3764 \mathrm{~g}$ catechol (Sigma Aldrich) was dissolved in $25 \mathrm{~mL}$ McIlvaine buffer. The prepared substrate solution was added to $250 \mathrm{~mL}$ McIlvaine buffer $(1+10)$ and stirred for 30 minutes to equilibrate. Two hundred $\mu \mathrm{L}$ of enzyme extract was added to 2.8 $\mathrm{mL}$ of substrate solution in the tube and mixed thoroughly, after which $\mathrm{h}$ the changes in absorbance at $420 \mathrm{~nm}$ were measured over time using a spectrophotometer. One unit of PPO activity was expressed as the change in absorbance of 0.1 per minute per $\mathrm{mL}$ of the enzyme extract.

\section{Statistics}

The results were analysed by means of Student's unpaired t test using the SPSS statistical package version 11.0 and a $p$ value of 0.05 was taken to be significant.

\section{RESULTS AND DISCUSSION}

The biochemical constituents of the cuttings before planting in the rooting media are shown in Table 1 . Total phenol was highest in the Dog ridge rootstock, while it was least in St. George. The 
maximum carbohydrate content was recorded in St. George, with the least carbohydrate measured in the $110 \mathrm{R}$ rootstock. The nitrogen content was highest in Dog ridge and was least in St. George. Similarly, reducing sugar content was highest in St. George and least in 110 R.

It is evident from Fig. 1 that significant differences in PPO activity were observed in the rootstocks during all the stages of experiments. Dog ridge had the highest PPO activity during the initial stages of the rooting process and significant differences in PPO activity in comparison with $110 \mathrm{R}$. A reduction in activity of PPO was recorded in the Dog ridge rootstock. On the $120^{\text {th }}$ day after planting, an increase in PPO activity in the same rootstock was recorded. In the $110 \mathrm{R}$ rootstock there was a decrease in PPO activity by the thirtieth day. The activity increased up to the ninth day after planting, and again a reduction in enzyme activity was recorded on the 120th day after planting. The least PPO activity was recorded in St. George at the initial stages of rooting, but it increased steadily from 30 days onwards until 120 days after planting.

Correspondingly, the number of root primordia was observed at different stages of the rooting process and there was a significant difference among rootstocks in inducing root primordial. The maximum number of primordia was recorded on St. George even at 120 days after planting, while the number was lowest on Dog ridge. Rootstock $110 \mathrm{R}$ put forth a moderate number of root primordia when observed 120 days after planting (Table 2).

Total root length was significantly varied among the rootstocks on the $120^{\text {th }}$ day after planting, with maximum root length in Dog ridge, followed by $110 \mathrm{R}$ and the shortest root length in St. George (Table 3).

The total number of roots also differed significantly among the rootstocks, with the maximum number of roots on St. George, followed by $110 \mathrm{R}$. Though St. George had a higher number of roots, they were very short and fibrous.

The activity of the PPO enzyme during the rooting process was measured in the three grape rootstocks used in this study to investigate the relationship between various biochemical constituents, PPO activity and rooting pattern.

It is evident from the table that PPO activity started increasing in St. George from planting until 120 days after planting, although the activity during initial stages was the least. Correspondingly, there was reduced phenolic content in the cuttings of St. George during the initial stages. PPO is involved in the oxidation of phenols and thus contributes energy for cell division and cell differentiation in the organogenesis of explants in tissue culture. Since the phenolic substrate was at a low level, the enzyme activity was also less. In contrast, Dog ridge and $110 \mathrm{R}$ had the highest phenolic content in the cuttings at the time of planting, which was acted upon by PPO and thus a greater number of rooting primordia were recorded on these two rootstocks in the initial stages, while the least number of primordia were recorded for St. George at 30 days after planting. Phenolic compounds are known to act synergistically with auxins and thus stimulate root initiation (Hartmann et al., 1993).

The sprouting percentage recorded 30 days after planting shows that more sprouts were recorded on St. George and the least on Dog ridge and $110 \mathrm{R}$. With the increase in number of days after planting, a corresponding increase in PPO activity was observed in the St. George cuttings (up to 120 days after planting). This may be
TABLE 2

Number of root primordia in grape rootstock cuttings during rooting process.

\begin{tabular}{cccc}
\hline \multirow{2}{*}{ Rootstocks } & \multicolumn{3}{c}{ Number of root primordia } \\
\cline { 2 - 4 } & 30 DAP* & 60 DAP & 120 DAP \\
\hline Dog ridge & $6.00 \pm 2.23 \mathrm{~b}$ & $8.00 \pm 1.02 \mathrm{c}$ & $9.00 \pm 1.52 \mathrm{c}$ \\
$\mathbf{1 1 0}$ R & $10.00 \pm 2.10 \mathrm{a}$ & $12.00 \pm 2.08 \mathrm{~b}$ & $15.00 \pm 2.30 \mathrm{~b}$ \\
St. George & $5.00 \pm 2.08 \mathrm{~b}$ & $16.00 \pm 2.09 \mathrm{a}$ & $23.00 \pm 3.05 \mathrm{a}$ \\
\hline
\end{tabular}

*DAP: Days after planting

The values are mean \pm SD of four replicates, and those marked with different alphabetic letters in the same column are significantly different at $\mathrm{p} \leq 0.05$.

Note: Data on 90 DAP was almost similar to that of 60 DAP. Hence, not shown in the table.

attributed to more sprouts, more leaves, better photosynthesis, and in turn the production of secondary metabolites such as phenols. The synthesised phenols may be acted upon by increased PPO activity at the base of the cuttings, which may also be a reason for the increased number of root primordia observed 120 days after planting. The trend of changes in PPO activity in the different rootstocks infers that rootstocks vary in their ability to root and generate more root initials (primordia). This corresponds to the findings of Coban (2007), who reported increased activity of PPO in Sultana, Round Seedless and Yalova incise during the early stages after planting and a decrease in activity after some time. Increased PPO activity continued throughout the experiment in Pembe Gemre and Cardinal cuttings. Similarly, Yilmaz et al. (2003) recorded PPO activity during the rooting of three grape varieties and reported increased PPO activity in two cultivars. They could not correlate PPO activity and rooting ability in the cuttings. Rios et al. (1997), in their studies on rooting responses in relation to enzymes such as peroxidase, PPO and IAA oxidase in walnut explants, reported a preferential increase of PPO and peroxidase activity during the induction phase. This was followed by decreased activity during the root manifestation stage, confirming that peroxidase and PPO activities are not involved in defining the initiation of root primordia. Apart from PPO, the total phenolic content itself may play a major role in the rooting process of cuttings. It is clear from the study that the rooting success was least on Dog ridge and 110R, which have a higher phenolic content in the cuttings at the initial stages after planting. Several authors have studied and reported that phenolics are negatively related to seed germination and in vitro proliferation (White, 1994; Prasad, 1999). In contrary, a positive correlation was observed between phenolics and totipotency (Thomas \& Ravindra, 1999). Some authors have reported that phenolics also affect respiratory enzymes in seed germination (Muscolo et al., 2001).

Phenolic compounds sometimes have an inhibitory or stimulating effect on plant growth, which varies from species to species (Ozyigit et al., 2007). Tung and Newton (2004) studied the browned and non-browned callus tissues of Virginia pine and detected a slightly enhanced level of PPO during the first three weeks. The level reached a maximum after three weeks in both cultures.

In the rooting of cuttings, the cut surfaces of the explants are important for phenol exudation and oxidation. Although phenols are being metabolised, they affect both regeneration and growth positively. If the surfaces are cut, then exudation and oxidation 
TABLE 3

Sprouting percentage, rooting success and root length in different grape rootstocks.

\begin{tabular}{cccc}
\hline Rootstocks & $\begin{array}{c}\text { Percentage sprouting } \\
\mathbf{( 3 0} \text { DAP*) }\end{array}$ & $\begin{array}{c}\text { Percentage rooting } \\
(\mathbf{1 2 0} \text { DAP) }\end{array}$ & $\begin{array}{c}\text { Total root length (cm) } \\
(\mathbf{1 2 0} \text { DAP) }\end{array}$ \\
\hline Dog ridge & $65.66 \pm 2.30 \mathrm{c}$ & $70.23 \pm 1.70 \mathrm{c}$ & $119.18 \pm 4.16 \mathrm{a}$ \\
$\mathbf{1 1 0 ~ R}$ & $70.33 \pm 1.15 \mathrm{~b}$ & $86.54 \pm 3.02 \mathrm{~b}$ & $85.98 \pm 3.60 \mathrm{~b}$ \\
St. George & $87.33 \pm 5.03 \mathrm{a}$ & $92.33 \pm 2.32 \mathrm{a}$ & $56.23 \pm 3.78 \mathrm{c}$ \\
\hline
\end{tabular}

*DAP: Days after planting

The values are mean $\pm \mathrm{SD}$ of four replicates, and those marked with different alphabetic letters in the same column are significantly different at $\mathrm{p} \leq 0.05$.

(PPO activity) take place in these surface cells. Especially in rooting parts of explants or young plantlets, phenol levels were affected negatively and no rooting was obtained, whilst high regeneration was observed (Ozyigit, 2008).

Apart from PPO activity, the other biochemical constituents of the cuttings in the initial stages of planting may also play an important role in the rooting of cuttings of different rootstocks. The possible reason for the reduction in the rooting percentage of Dog ridge rootstock may be a higher content of rooting inhibitors and lower concentration of auxins. In his study on the relationship between carbohydrates and nitrogen and the rooting of stem cuttings, Sturve (1982) reported that a higher $\mathrm{C}: \mathrm{N}$ ratio in cutting tissues promoted rooting, but did not accurately predict the degree of the rooting response. The $\mathrm{C}: \mathrm{N}$ ratio of Dog ridge was the least in comparison to that of the other rootstocks, which may be one of the reasons for the reduced rooting percentage of this rootstock. Sadhu and Bose (1982) reported that the levels of soluble sugar and the $\mathrm{C}: \mathrm{N}$ ratio correlated positively with rooting in guava. Spiegel (1954) used chromatography to suggest the presence of two inhibitors associated with the rooting response of grapes. Many of the workers who have thoroughly tested the status of the $\mathrm{C}: \mathrm{N}$ ratio of mother vines and rooting ability have stated that a $\mathrm{C}: \mathrm{N}$ ratio that is too high or too low is not favourable for rooting success. This corresponds with the findings of the present study, namely that $110 \mathrm{R}$ had a very high C:N ratio, Dog ridge had a very low $\mathrm{C}: \mathrm{N}$ ratio while the $\mathrm{C}: \mathrm{N}$ ratio of St. George was in between, which might have favoured the higher rooting success in this rootstock.

\section{CONCLUSIONS}

From this study it is clear that the rooting behaviour of grape rootstocks varies with the species to which the rootstock belongs and that PPO does not have any influence on an increase in shoot length from the cuttings. However, it was also observed that PPO may be involved in the formation of root primordia through its function in cell division, cell elongation and dedifferentiation, as it was evident from the study that there was higher PPO activity in St. George even at 120 days after planting, which resulted in more root primordia. Total root length was maximum in Dog ridge and $110 \mathrm{R}$, which had the least PPO activity in the later stages of the experiment.

\section{LITERATURE CITED}

Coban, H., 2007. Determination of polyphenol oxidase activity during rooting in cuttings of some grape varieties (Vitis vinifera L). Asian J. Chem. 19, 4020-4024.

Dalet, F. \& Cornu, D., 1988. Lignification levels and peroxidase activity during in vitro rooting of Prunus avium. Can. J. Bot. 67, 2192-2186.
Gonazales, R., Sanchez, R. \& Rodriguez, R., 1991. Ethylene in relation to proteins, peroxidase and polyphenol oxidase activities during rooting in hazelnut cotyledons. Physiol. Plantarum 83, 611-620.

Hahlbrock, K. \& Griesbach, H., 1979. Enzymatic controls in the biosynthesis of lignin and flavonoids. Ann. Rev. Plant Physiol. 30, 105-136.

Haplin, B.E. \& Lee, C.Y., 1987. Effect of blanching on enzyme activity and quality changes in green peas. J. Food Sci. 52, 1002-1005.

Hartmann, H.T., Kester, D.E. \& Davies, F.T., 1993. Plant propagation - principles and practices. Prentice Hall, New Delhi, India.

Huystee, R.B. \& Cairns, W.L., 1982. Progreno and prospects in the use of peroxidase to study cell development. Phytochem. 21, 1843-1847.

Kim, J.Y., Seo, S.Y., Kim, S.K., Sung, S.K., Song, K.J., An, G. \& Kim, W.T., 2001. Two polyphenol oxidases are differentially expressed during vegetative and reproductive development and in response to wounding of Fuji apple. Plant Sci. $161,1145-1152$

Muscolo, A., Panuccio, M.R. \& Sidari, M., 2001. The effect of phenols on respiratory enzymes in seed germination. Plant Growth Regl. 35, 31-35.

Ozyigit, I.I., 2008. Phenolic changes during in vitro organogenesis of cotton (Gossypium hirsutum L). Afr. J. Biotech. 7, 1145-1150.

Ozyigit, I.I., Kahramanz, M.V. \& Ecranz, O., 2007. Relationship between explant age, total phenols and regeneration response in tissue cultured cotton (Gossypium hirsutum L.). Afr. J. Biotech. 6, 3-8.

Prasad, R., 1989. Effect of nonyl phenol adjuvant on macrophytes. In: Chow, P.N.P. (ed). Adjuvant and agrochemicals; mode of action and physiology activity. CRC Press, Boca Raton FL, USA.

Rios, D.G., Sanchez-Olate, M.E., Gea, M.A., Revilla, M.A. \& Rodrigues, R., 1997. Rooting response in relation to PO, PPO, IIA O activities in walnut explants. In: Proc. III Intern. Walnut Congress, Alcobaça, Portugal. Acta Horticulturae 442, 241249.

Sadhu, M.K. \& Bose, S., 1982. Proc. 21 ${ }^{\text {st }}$ Hort. Congress, Hamburg, Germany. p. 1379.

Satisha, J., Ramteke, S.D. \& Karibasappa, G.S., 2007. Physiological and biochemical characterization of grape rootstocks. S. Afr. J. Enol. Vitic. 28, 163-168.

Singleton, V.L. \& Rossi, J.A., 1965. Colorimetry of total phenolics with phosphomolybdic - phosphotungstic acid reagents. Am. J. Enol. Vitic. 16, 144158.

Spiegel, P., 1954. Auxins and inhibitors in canes of Vitis. Bull. Res. Council Israel 4, 176-183.

Sturve, D.K., 1981. The relation between carbohydrates, nitrogen and rooting of stem cuttings. The Plant Propagator 27, 6-7.

Tang, W. \& Newton, R.J., 2004. Increase of polyphenol oxidase and decrease of polyamines correlate with tissue browning in Virginia pine (Pinus virginiana Mill). Plant Sci. 167, 621-628.

Thomas, P. \& Ravindra, M.B., 1999. Shoot tip culture in mango: influence of medium, genotype, explants factors, season and decontamination treatments on phenolic exudation, explant survival and axenic culture establishment. J. Hort. Sci. 72, 713-722

White, R., 1994. Environmentally persistent alkylphenolic compounds are estrogenic. Endochrinol. 135, 175-182.

Yilmaz, H., Taskin, T. \& Otludil, B., 2003. Polyphenol oxidase activity during rooting in cuttings of grapes (Vitis vinifera L) varieties. Turkish J. Bot. 27, 495-498. 